\title{
Commentary: The effects of acute stress on core executive functions: A meta-analysis and comparison with cortisol
}

\author{
Junhua Dang * \\ Department of Psychology, Lund University, Lund, Sweden
}

Keywords: stress, executive functions, working memory, inhibition (psychology), task-switching

\section{A commentary on}

The effects of acute stress on core executive functions: A meta-analysis and comparison with cortisol

by Shields, G. S., Sazma, M. A., and Yonelinas, A. P. (2016). Neurosci. Biobehav. Rev. 68, 651-668. doi: 10.1016/j.neubiorev.2016.06.038

OPEN ACCESS

Edited by:

Mattie Tops,

VU University Amsterdam,

Netherlands

Reviewed by:

Juan Yang,

Southwest University, China

*Correspondence:

Junhua Dang

junhua.dang@psy.lu.se

Specialty section:

This article was submitted to

Cognition,

a section of the journal

Frontiers in Psychology

Received: 03 August 2017 Accepted: 19 September 2017 Published: 28 September 2017

Citation:

Dang J (2017) Commentary: The effects of acute stress on core

executive functions: A meta-analysis and comparison with cortisol.

Front. Psychol. 8:1711.

doi: 10.3389/fpsyg.2017.01711
Recently, Shields et al. conduct a meta-analysis that summarized the effects of acute stress on core executive functions (Shields et al., 2016). It was found that stress impaired working memory and cognitive flexibility. The effect of stress on inhibition was nuanced, such that it impaired cognitive inhibition but enhanced response inhibition. This effortful work advanced our understanding of the relationship between stress and executive functions to a great extant.

While acknowledging its contribution, we suggest that cautious attention has to be paid to the categorizations of tasks measuring inhibition in this paper. Shields et al. (2016) defined response inhibition as "the suppression of a proponent response" and cognitive inhibition as "selectively attending to or ignoring information" (p. 654). Subsequently, as shown in their Table 1, they coded tasks measuring response inhibition and cognitive inhibition. However, after carefully scrutinizing each task, we argue that these categorizations are problematic and thus the conclusion might be misleading.

First, it was difficult for the reader to follow why the forward span task was coded as a task measuring cognitive inhibition. The span task is in general used to measure working memory. The forward span version requires participants to repeat the sequence of a group of stimuli that were just shown to them. The backward span version requires repeating in reversed order. Correspondingly, the forward span version is assumed to measure temporary storage of working memory whereas the backward span measures the manipulation process of working memory (e.g., Quesada et al., 2012). Shields et al. (2016) did code the backward span task as working memory measurement. However, their coding of the forward span task as cognitive inhibition should be doubted.

In any case, it would be interesting to test whether acute stress influences performance of the forward span task. In Shields et al.'s (2016) paper, there were five studies that used the forward span task. Meta-analysis showed a non-significant result, $g=-0.06, Z=-0.48, p=0.628$, 95\% $\mathrm{CI}=[-0.28,0.17]$, with low heterogeneity, $Q(4)=4.71, p=0.318$. Therefore, combined with Shields et al.'s (2016) finding regarding the effect of stress on performance of the $N$-back task and the backward span task, it seems that although stress impairs the manipulation process of working memory, it may not influence temporary storage of working memory. 
TABLE 1 | Inhibition Tasks included in Shields et al.'s Meta-Analysis.

\begin{tabular}{|c|c|c|c|c|c|}
\hline Author(s) & $g$ & $95 \% \mathrm{Cl}$ & Inhibition task & Original coding & New coding \\
\hline Chajut and Algom, 2003 & 0.61 & {$[0.27,0.95]$} & Stroop & Response inhibition & Response inhibition \\
\hline Ishizuka et al., 2007 & -0.01 & {$[-0.53,0.50]$} & Stroop & Response inhibition & Response inhibition \\
\hline Cackowski et al., 2014 & 0.21 & {$[-0.18,0.59]$} & Go/stop task & Response inhibition & Response inhibition \\
\hline Finy et al., 2014 & 0.14 & {$[-0.27,0.55]$} & Go/no-go & Response inhibition & Response inhibition \\
\hline Vinski and Watter, 2013, Exp. 2 & -0.19 & {$[-0.75,0.38]$} & SART & Cognitive inhibition & Response inhibition \\
\hline Vinski and Watter, 2013, Exp. 1 & -0.21 & {$[-0.57,0.15]$} & SART & Cognitive inhibition & Response inhibition \\
\hline Alomari et al., 2015 & -0.75 & {$[-1.44,-0.06]$} & SART & Cognitive inhibition & Response inhibition \\
\hline Cornelisse et al., 2011 & -0.11 & {$[-0.79,0.57]$} & d2 test & Cognitive inhibition & Cognitive inhibition \\
\hline Sato et al., 2012 & 0.18 & {$[-0.70,1.06]$} & Flanker & Cognitive inhibition & Cognitive inhibition \\
\hline Quesada et al., 2012 & -0.04 & {$[-0.64,0.56]$} & Span forward & Cognitive inhibition & Not inhibition \\
\hline Hoffman and al'Absi, 2004 & -0.08 & {$[-0.49,0.34]$} & Span forward & Cognitive inhibition & Not inhibition \\
\hline Schoofs et al., 2009 & -0.11 & {$[-0.57,0.35]$} & Span forward & Cognitive inhibition & Not inhibition \\
\hline Taverniers et al., 2010 & -0.70 & {$[-1.47,0.06]$} & Span forward & Cognitive inhibition & Not inhibition \\
\hline Mahoney et al., 2007 & -0.91 & {$[-1.47,-0.34]$} & Simple RT and VA & Cognitive inhibition & Not inhibition \\
\hline McMorris et al., 2006 & -0.08 & {$[-0.74,0.58]$} & Simple RT & Cognitive inhibition & Not inhibition \\
\hline Sorg and Whitney, 1992 & 0.15 & {$[-0.23,0.53]$} & Word span & Cognitive inhibition & Not inhibition \\
\hline
\end{tabular}

Original coding, Categorizations in Shields et al.'s analysis; New coding, Categorizations in the current analysis; SART, the sustained attention to response task, a typical go/no-go task; EIT, the emotional interference task, which was called as the emotional Stroop task by Shields et al. Simple RT, the simple reaction time task; VA, the visual attention task; Finy et al. (2014), this reference is not included in the reference list because Shields et al. did not report this reference and it could not be found through literature searching.

Second, two studies that used the simple reaction time task (McMorris et al., 2006; Mahoney et al., 2007) were also coded as cognitive inhibition by Shields et al. (2016). In this task, participants were presented with a series of visual stimuli at one of four different locations on the screen and required to indicate the correct spatial location of each stimulus by striking one of four corresponding keys. Mahoney et al. (2007) employed a visual attention task that was also coded as cognitive inhibition. This task required participants to detect a small, faint stimulus that randomly appeared for $1 \mathrm{~s}$ at different locations. In addition, Sorg and Whitney (1992) used a word span task that was also coded as cognitive inhibition. This task was very similar to the forward span, in which participants had to recall a set of words in order of presentation. From the task descriptions, it seems apparent that these tasks can hardly be coded as tasks measuring cognitive inhibition.

Third, four studies used the sustained attention to response task (SART). Although with a different name, this task is actually a typical go/no-go task in which participants are required to respond quickly and accurately on non-target trials but withhold response on infrequent target trials. There were also two studies explicitly stated that they used the go/no-go task. Shields et al. (2016) coded these four studies using the SART as cognitive inhibition but coded the two studies using the go/no-go task as response inhibition. If we follow Shields et al.'s (2016) definitions of response inhibition and cognitive inhibition, it might be more suitable to code the go/no-go task as well as the SART as response inhibition. Then we did a meta-analysis by including all the studies using response inhibition tasks, as shown in Table 1, which yielded a non-significant result, $g=0.06, Z=-0.51$, $p=.611,95 \% \mathrm{CI}=[-0.17,0.29]$, with high heterogeneity, $Q(9)=$ $21.11, p=0.012$. Even if we restricted the analysis only to studies using the go/no-go task and the SART, the result was still nonsignificant, $g=-0.13, Z=-1.26, p=0.207,95 \% \mathrm{CI}=[-0.32$, 0.07 , with low heterogeneity, $Q(5)=5.24, p=0.388$. Therefore, it might be safer to conclude that the effect of stress on response inhibition is pending, considering the small number of studies included.

Finally, after excluding abovementioned tasks that were coded as cognitive inhibition by Shields et al. (2016) in an inappropriate way, there were four studies left in the category of cognitive inhibition. Still, whether they can be coded as cognitive inhibition according to Shields et al.'s (2016) definition is debatable. For example, Sänger et al. (2014) employed a novel task that had never been used before, which makes the validity unclear. Giles et al. (2015) used a delayed match-to-sample task with distracters presented during the delay period. The delayed matched-to-sample was coded as a task measuring working memory by Shields et al. (2016). It might be difficult to categorize Giles et al.'s (2015) task as cognitive inhibition just because it included distracters. Although the $\mathrm{d} 2$ test of attention (Cornelisse et al., 2011) and the Flanker task (Sato et al., 2012) seem 
consistent with Shields et al.'s definition of cognitive inhibition, the effect size directions of the studies using these two tasks were opposite, and both effect sizes were negligible. Therefore, the effect of stress on cognitive inhibition should also be pending.

Overall, we suggest unlike working memory and cognitive flexibility, the effect of stress on inhibition, no matter response

\section{REFERENCES}

Alomari, R. A., Fernandez, M., Banks, J. B., Acosta, J., and Tartar, J. L. (2015). Acute stress dysregulates the LPP ERP response to emotional pictures and impairs sustained attention: time-sensitive effects. Brain sci. 5, 201-219. doi: 10.3390/brainsci5020201

Banks, J. B., Tartar, J. L., and Welhaf, M. S. (2014). Where's the impairment: an examination of factors that impact sustained attention following a stressor. Cogn. Emot. 28, 856-866. doi: 10.1080/02699931.2013. 857643

Cackowski, S., Reitz, A. C., Ende, G., Kleindienst, N., Bohus, M., Schmahl, C., et al. (2014). Impact of stress on different components of impulsivity in borderline personality disorder. Psychol. Med. 44, 3329-3340. doi: 10.1017/S0033291714000427

Chajut, E., Algom, D. (2003). Selective attention improves under stress: implications for theories of social cognition. J. Pers. Soc. Psychol. 85, 231-248. doi: 10.1037/0022-3514.85.2.231

Cornelisse, S., Joëls, M., and Smeets, T. (2011). A randomized trial on mineralocorticoid receptor blockade in men: effects on stress responses, selective attention, and memory. Neuropsychopharmacology 36, 2720-2728. doi: $10.1038 /$ npp.2011.162

Giles, G. E., Mahoney, C. R., Urry, H. L., Bruny,é, T. T., Taylor, H. A., and Kanarek, R. B. (2015). Omega-3 fatty acids and stress-induced changes to mood and cognition in healthy individuals. Pharmacol. Biochem. Behav. 132, 10-19. doi: 10.1016/j.pbb.2015.02.018

Hendricks, M. A. (2013). An Exploration of the Relationship between Emotional and Cognitive Control, Doctoral Dissertation, Saint Louis University.

Hoffman, R., and al'Absi, M. (2004). The effect of acute stress on subsequent neuropsychological test performance (2003). Arch. Clin. Neuropsychol. 19, 497-506. doi: 10.1016/j.acn.2003.07.005

Ishizuka, K., Hillier, A., and Beversdorf, D. Q. (2007). Effect of the cold pressor test on memory and cognitive flexibility. Neurocase 13, 154-157. doi: 10.1080/13554790701441403

Kuhlmann, S., Piel, M., and Wolf, O. T. (2005). Impaired memory retrieval after psychosocial stress in healthy young men. J. Neurosci. 25, 2977-2982. doi: 10.1523/JNEUROSCI.5139-04.2005

Mahoney, C. R., Castellani, J., Kramer, F. M., Young, A., and Lieberman, H. R. (2007). Tyrosine supplementation mitigates working memory decrements during cold exposure. Physiol. Behav. 92, 575-582. doi: 10.1016/j.physbeh.2007.05.003

McMorris, T., Swain, J., Smith, M., Corbett, J., Delves, S., Sale, C., et al. (2006). Heat stress, plasma concentrations of adrenaline, noradrenaline, inhibition or cognitive inhibition, is in need of further investigation.

\section{AUTHOR CONTRIBUTIONS}

The author confirms being the sole contributor of this work and approved it for publication.

5-hydroxytryptamine and cortisol, mood state and cognitive performance. Int. J. Psychophysiol. 61, 204-215. doi: 10.1016/j.ijpsycho.2005.10.002

Quesada, A. A., Wiemers, U. S., Schoofs, D., and Wolf, O. T. (2012). Psychosocial stress exposure impairs memory retrieval in children. Psychoneuroendocrinology 37, 125-136. doi: 10.1016/j.psyneuen.2011.05.013

Sänger, J., Bechtold, L., Schoofs, D., Blaszkewicz, M., and Wascher, E. (2014). The influence of acute stress on attention mechanisms and its electrophysiological correlates. Front. Behav. Neurosci. 8:353. doi: 10.3389/fnbeh.2014.00353

Sato, H., Takenaka, I., and Kawahara, J. I. (2012). The effects of acute stress and perceptual load on distractor interference. Q. J. Exp. Psychol. 65, 617-623. doi: 10.1080/17470218.2011.648944

Schoofs, D., Wolf, O. T., and Smeets, T. (2009). Cold pressor stress impairs performance on working memory tasks requiring executive functions in healthy young men. Behav. Neurosci. 123, 1066-1075. doi: 10.1037/a0016980

Schwabe, L., Höffken, O., Tegenthoff, M., Wolf, O. T. (2013). Stress-induced enhancement of response inhibition depends on mineralocorticoid receptor activation. Psychoneuroendocrinology 38, 2319-2326. doi: 10.1016/j.psyneuen.2013.05.001

Shields, G. S., Sazma, M. A., and Yonelinas, A. P. (2016). The effects of acute stress on core executive functions: a meta-analysis and comparison with cortisol. Neurosci. Biobehav. Rev. 68, 651-668. doi: 10.1016/j.neubiorev.2016.06.038

Sorg, B. A., and Whitney, P. (1992). The effect of trait anxiety and situational stress on working memory capacity. J. Res. Pers. 26, 235-241. doi: 10.1016/0092-6566(92)90041-2

Taverniers, J., Van Ruysseveldt, J., Smeets, T., and von Grumbkow, J. (2010). Highintensity stress elicits robust cortisol increases, and impairs working memory and visuo-spatial declarative memory in Special Forces candidates: a field experiment. Stress 13, 324-334. doi: 10.3109/10253891003642394

Vinski, M. T., and Watter, S. (2013). Being a grump only makes things worse: a transactional account of acute stress on mind wandering. Front. Psychol. 4:730. doi: 10.3389/fpsyg.2013.00730

Conflict of Interest Statement: The author declares that the research was conducted in the absence of any commercial or financial relationships that could be construed as a potential conflict of interest.

Copyright (C) 2017 Dang. This is an open-access article distributed under the terms of the Creative Commons Attribution License (CC BY). The use, distribution or reproduction in other forums is permitted, provided the original author (s) or licensor are credited and that the original publication in this journal is cited, in accordance with accepted academic practice. No use, distribution or reproduction is permitted which does not comply with these terms. 